\title{
BMJ Open Screen time of infants in Sydney, Australia: a birth cohort study
}

\author{
Meena Chandra, ${ }^{1}$ Bin Jalaludin, ${ }^{2,3,4}$ Susan Woolfenden, ${ }^{5,6}$ Joseph Descallar, ${ }^{3,7}$ \\ Laura Nicholls, ${ }^{8,9}$ Cheryl Dissanayake, ${ }^{10}$ Katrina Williams, ${ }^{11,12,13}$ \\ Elisabeth Murphy, ${ }^{14}$ Amelia Walter, ${ }^{6,8}$ John Eastwood, ${ }^{1,3}$ Valsamma Eapen, ${ }^{3,8,9}$ \\ The Watch Me Grow Study Group
}

To cite: Chandra M, Jalaludin B, Woolfenden S, et al. Screen time of infants in Sydney, Australia: a birth cohort study. BMJ Open 2016;6:e012342.

doi:10.1136/bmjopen-2016012342

- Prepublication history for this paper is available online. To view these files please visit the journal online (http://dx.doi.org/10.1136/ bmjopen-2016-012342).

Received 20 April 2016 Revised 2 September 2016 Accepted 8 September 2016

CrossMark

For numbered affiliations see end of article.

\section{Correspondence to} Dr Meena Chandra; meenakshi.chandra@sswahs. nsw.gov.au and Valsamma Eapen; v.eapen@ unsw.edu.au

\section{ABSTRACT}

Objectives: To determine the amount of daily screen time in children 18 months of age and ascertain correlations that may be contributing to excessive screen use.

Design: A birth cohort was followed with telephone interviews at 6,12 and 18 months of age. Information about screen time was collected at 18 months.

Setting: Parents were recruited from postnatal wards of 2 major public hospitals and at home visits

conducted for new mothers within 4 weeks of birth in South Western Sydney (SWS).

Participants: Parents of 500 children with infants 18 months of age residing in SWS.

Primary and secondary outcomes: Screen time in infants 18 months of age and associated correlations.

Results: A large percentage of children 18 months of age $(40 \%)$ had screen times $>2$ hours daily. There were significant associations between more than 2 hours of screen time daily and mothers without a partner (OR 4.32 (95\% Cl 1.67 to 11.15 )); having <3 siblings (no siblings: OR 2.44 ( $95 \% \mathrm{Cl} 1.20$ to 4.94$) ; 1-2$ siblings: OR 2.08 (95\% Cl 1.06 to 4.08)); an employed father (OR 1.96 (95\% $\mathrm{Cl} 1.09$ to 3.52$)$ ); no outdoor equipment at home (OR $1.89(95 \% \mathrm{Cl} 1.08$ to 3.34$))$ and fewer than 5 outings per week (OR $2.08(95 \% \mathrm{Cl}$ 1.37 to 3.17$)$ ).

Conclusions: There is emerging evidence that excess screen time in children causes adverse cognitive, developmental and health outcomes. This study has shown that a large proportion of very young children residing in SWS have screen exposures for $>2$ hours per day. Factors contributing to excess screen time have also been identified in this study; however, a greater understanding of risk factors needs to be ascertained in order to facilitate greater public health efforts to reduce screen exposure.

\section{INTRODUCTION}

The Australian Department of Health recommends that children below the age of 2 years watch no television and children between 2 and 5 years of age watch no more than 1 hour of television daily. The American

\section{Strengths and limitations of this study}

- The study uses a prospective sample where comprehensive individual-level data on a large birth cohort with follow-up at 18 months of age was collected.

- This study is one of the very few to investigate screen time in children $<2$ years of age, a significant period in child development.

- There is potential for measurement errors from self-reporting of screen times by parents.

Academy of Paediatrics and the Royal Australasian College of Physicians have similar recommendations and extend television viewing to high-quality age-appropriate content only. ${ }^{1}{ }^{2}$ Many studies have shown that adherence to these guidelines is low. For example, national surveys conducted in the USA found that $17 \%$ of children aged $0-11$ months and $48 \%$ of children aged $12-23$ months watched more than 2 hours of television daily. ${ }^{3}$ At 4 months of age in Australia, children were watching $44 \mathrm{~min}$ of television daily and this extended to 2.5 hours by 4 years of age. By 5 years and older, $70 \%$ of children were exceeding the daily limit. ${ }^{4-6}$

Longitudinal studies and systematic reviews have found that children older than 5 years of age who watched more than 2 hours of television per day were more likely to be overweight, have reduced cardiorespiratory fitness, have high cholesterol levels, sleep disturbances, musculoskeletal disorders and engage in smoking in adulthood. ${ }^{4}$ 7-11 Reasons for these adverse health effects include television viewing displacing children from more energy expending activities; the influence of content (that may promote unhealthy lifestyles and behaviours) and sustained awkward postures while watching television. ${ }^{4} 8$

Excess screen time has also been associated with higher rates of behavioural 
problems. Primary school aged children who watched more than 2 hours of television per day were more likely to have higher Child Behaviour Checklist (CBCL) scores in the domains of withdrawn behaviour, attention, externalising behaviours and total problems. Higher CBCL scores have been shown to be a precursor for significant adverse behavioural and mental health outcomes. ${ }^{9} 10$ These adverse effects have also been extended to developmental domains in many cognitive areas from language, comprehension and attention to mathematics. ${ }^{7} 8^{10-15} \mathrm{~A}$ longitudinal study conducted in the USA on 3-year-old children found negative cognitive outcomes at 6 and 7 years of age with excess screen time. ${ }^{2}$ Other studies have found negative associations between television exposure and attention, reading comprehension, and mathematics in children aged $<3$ years. ${ }^{2} 1315 \mathrm{~A}$ randomised control trial conducted in 6-year-old children showed modest but significant improvements in intelligence tests and attention time on cognitive tasks when television viewing time was reduced over a 6 -week period. ${ }^{2}$ Background television also has an adverse impact in infants with another study finding that duration of toy play and sustained attention was reduced when the television was switched on. ${ }^{16}$ The majority of evidence so far has been from cross-sectional studies and therefore causation cannot be assumed.

Screen exposure in children has also been reported to have some benefits. For example, educational programmes can improve cognition and general knowledge in children 3-5 years of age, and are also successful in enhancing their social and emotional development. ${ }^{11}$ However, the majority of television viewed by children is not educational in nature. ${ }^{2}$

Risk factors for excess screen time in children are yet to be established. This is an important area of research in terms of public health interventions to reduce sedentary activity in children. A systematic review in children under 3 years of age found correlations between high screen time and a child's age (older) and ethnicity (minority), while increased cognitive stimulation in the home environment (in the form of educational toys, time spent reading to children, etc) was associated with less screen time. ${ }^{12}$ Associations between parental age, education and employment; number of siblings; and household income have been unclear. ${ }^{12-14}$

The aim of the current study was to determine the average amount of daily screen time (television, DVDs, electronic games) in children 18 months of age residing in South Western Sydney (SWS) and ascertain correlations that may be contributing to excess screen exposure in this sample.

\section{METHODS}

\section{Setting}

The study used data collected from a larger birth cohort study, the Watch Me Grow (WMG) study. Briefly, the WMG study was designed to evaluate the performance of the current developmental surveillance system in accurately identifying children at risk of developmental disorders in SWS. The birth cohort was followed with telephone interviews at 6,12 and 18 months of age. The WMG study protocol has been previously reported. ${ }^{17}$ Information about screen time was collected at the 18-month follow-up.

SWS is the largest and fastest growing region in New South Wales (NSW), Australia, and has one of the most socioeconomically disadvantaged communities in the state. Along with the accompanying health and psychosocial problems associated with disadvantaged populations, it also experiences higher rates of unemployment compared with the state average and has a high percentage of families that are welfare dependent. ${ }^{18}$

\section{Recruitment and sample size}

Data were collected from families of 500 children through self-reported baseline and 18-month questionnaires. Screen time information was not available for 10 children and a further 39 children were excluded from the study as they were $\geq 2$ years of age at the time of the follow-up questionnaire, leaving 451 children for the analysis.

Recruitment was conducted between November 2011 and April 2013. Trained research staff visited the postnatal wards of two major public hospitals in SWS daily and recruited 1866 women who had just given birth. In addition, a further 159 new mothers were recruited through child and family health nurses who conduct home visits with new mothers within 4 weeks of birth. Detailed recruitment strategies have been previously published. No incentives were given to the cohort to participate in the study. ${ }^{19}$

\section{Participant recruitment}

Of the 2025 recruited participants, 1761 (87\%) completed a baseline questionnaire at enrolment and 500 (25\%) participants completed the 18-month questionnaire via telephone interviews, which took $10-15 \mathrm{~min}$ to complete.

When the WMG infants were compared with infants born in all major public hospitals in SWS Local Health District (SWSLHD) who were not recruited for the entire study period, there were significantly less males. Also more WMG infants were preterm, had low birth weights and were admitted to the special care nursery. Further a significantly greater number of WMG infant mothers had antenatal problems. Less WMG infants had mothers who smoked in the second half pregnancy, and did not have a partner.

\section{Analysis of representativeness}

Electronic medical record (EMR) data from all infants born in a public hospital in SWSLHD and their mothers during the study period were extracted from the SWSLHD medical records database and compared with the WMG cohort to establish representativeness. ${ }^{19}$ 


\section{Outcome-screen time}

The 18-month questionnaire, apart from asking questions about sociodemographic characteristics, developmental surveillance and the home environment, also included a question on daily screen time which was 'How much 'screen time' (television, DVDs, electronic games) does your child get per day?' with six options to select from: '0-2; 2-4; 4-6; 6-8 hours; more than 8 hours and don't know'. The data collected were then recoded into two categories, $\leq 2$ hours daily and $>2$ hours daily. Questionnaires were administered by bilingual researchers (eg, Arabic, Vietnamese, Hindi and Chinese) where appropriate. Three call backs were attempted and then a text message left when participants did not respond.

\section{Correlations}

Based on the current literature, information on the following variables were extracted from the baseline and 18-month questionnaires: infant gender; parental age (mother: $\leq 30$, >30 years; father: $\leq 33,>33$ years); parental employment status (full/part time; home/student/ unemployed); parental education level (University/ Tertiary and Further Education college (TAFE); high school); parental country of birth (Australia, other) and mother's marital status (has a partner which included married or de facto relationship; and no partner which included divorced or separated). Information on annual household income after tax $(<\$ A 25000 ; \quad \$ A 25-$ \$A75 000; \$A75 001-\$A105 000; > \$A105 000); primary language at home (English; other); number of siblings (nil; 1-2; 3+); presence of outdoor activity equipment in the home (for climbing, riding, outdoors; yes; no); the number of outings per week $(0-4 ; 5+)$; the number of stories read to the child per week $(\leq 3 ;>3)$ and childcare attendance (centre based; non-centre based; mixed care; no care) was also collected. Each questionnaire was checked prior to data entry and any missing or ambiguous answers were asked again at another telephone interview or when parents were seen at developmental assessments.

\section{Ethics}

Ethics approval for the WMG study was obtained from the SWSLHD Human Research Ethics Committee. All the participants (parents of infants) provided written informed consent.

\section{Statistical analyses}

Associations between categorical variables were established using contingency tables and $\chi^{2}$ tests. The t-tests and, where appropriate, non-parametric tests were used for continuous variables. Multivariable logistic regression analyses were used to determine independent factors associated with screen time. Variables with a $\mathrm{p}$ value of $<0.20$ in single variable logistic regression models were included in the initial multivariable logistic regression model. The backward selection method was used to determine the final model. Effect estimates are presented as ORs with associated 95\% CIs. A p value of $<0.05$ denoted statistical significance. SAS V.9.4 (SAS Institute, Cary, North Carolina, USA) was used to conduct all analyses.

\section{RESULTS}

Sociodemographic and household characteristics of the cohort completing the 18-month questionnaire are presented in table 1 . There were more female than male infants in the study $(53.2 \%, 46.8 \%)$. The majority of mothers had a partner $(92 \%)$, were $>30$ years of age at the time of delivery $(53 \%)$ and were born outside Australia $(52.5 \%)$. Similar numbers of mothers were working (before birth) compared with either being a student, at home or unemployed. Approximately $64 \%$ of mothers and fathers had completed high school and most household annual incomes were between $\$$ A25 000 and \$A75 $000(54.8 \%)$. Most fathers $(53.2 \%)$ were above 33 years of age, born outside Australia (54.9\%) and were in full-time employment $(83.8 \%)$. The majority of infants had at least one other sibling (66.3\%) and 29.7\% of families did not speak English at home. There were equal numbers of children attending either no childcare or some form of formal or informal childcare. Finally, most households contained outdoor activity equipment (for climbing and riding; 84.7\%), had more than five outings/week $(63.6 \%)$ and $62.6 \%$ of children had greater than three stories read to them weekly $(37.4 \%$ had less than three stories read weekly).

\section{Screen time and factors associated with more than 2 hours of screen time a day}

The majority of children $(60.8 \%)$ had screen times between 0 and 2 hours per day, with $39.2 \%$ having screen times for $>2$ hours daily. In a multivariable logistic regression model, there were significant associations between more than 2 hours of screen time daily and mothers without a partner (OR $4.32 \quad(95 \%$ CI 1.67 to 11.15)); having less than three siblings (no siblings: OR 2.44 (95\% CI 1.20 to 4.94); 1-2 siblings: OR 2.08 (95\% CI 1.06 to 4.08)); an employed father (OR 1.96 (95\% CI 1.09 to 3.52)); no outdoor equipment at home (OR 1.89 (95\% CI 1.08 to 3.34)) and fewer than five outings per week (OR 2.08 (95\% CI 1.37 to 3.17) (table 2).

\section{DISCUSSION}

In our birth cohort, $40 \%$ of infants $\sim 18$ months of age were using screens (television, DVDs, electronic games) for more than 2 hours each day which exceeds current recommended guidelines. ${ }^{1} \quad{ }^{2}$ Significant associations were found between increased screen time and less than five outings per week, not having outdoor equipment in the home, being a single mother, having fewer siblings, and a father who was employed. 
Table 1 Sociodemographic and household characteristics by daily screen time $(\mathrm{N}=451)$

\begin{tabular}{|c|c|c|c|c|}
\hline Variable & N (\%) & $\begin{array}{l}\leq 2 \text { hours/day } \\
\text { screen time } \\
\mathrm{N}(\%)\end{array}$ & $\begin{array}{l}>2 \text { hours/day } \\
\text { screen time } \\
\mathrm{N}(\%)\end{array}$ & p Value \\
\hline \multicolumn{5}{|l|}{ Child's gender } \\
\hline Female & $240(53.2)$ & $143(59.6)$ & $97(40.4)$ & \multirow[t]{2}{*}{0.587} \\
\hline Male & $211(46.8)$ & $131(62.1)$ & $80(37.9)$ & \\
\hline \multicolumn{5}{|l|}{ Whether mother has a partner } \\
\hline Partner & $451(92)$ & $260(62.7)$ & $155(37.3)$ & \multirow[t]{2}{*}{0.005} \\
\hline No partner & $36(8)$ & $14(38.9)$ & $22(61.1)$ & \\
\hline \multicolumn{5}{|l|}{ Mothers age at delivery (years) } \\
\hline$>30$ & $239(53)$ & $151(63.2)$ & $88(36.8)$ & \multirow[t]{2}{*}{0.263} \\
\hline$\leq 30$ & $212(47)$ & $123(58.0)$ & 89 (42.0) & \\
\hline \multicolumn{5}{|l|}{ Mother's country of birth } \\
\hline Australia & $214(47.5)$ & $136(63.6)$ & $78(36.4)$ & \multirow[t]{2}{*}{0.248} \\
\hline Other & $237(52.5)$ & $138(58.2)$ & 99 (41.8) & \\
\hline \multicolumn{5}{|l|}{ Mother's employment status } \\
\hline Full/part time & 222 (49.3) & $126(56.8)$ & 96 (43.2) & \multirow[t]{2}{*}{0.076} \\
\hline Other (at home/student/unemployed) & $228(50.7)$ & $148(64.9)$ & $80(35.1)$ & \\
\hline \multicolumn{5}{|l|}{ Mother's highest education level } \\
\hline High school & $284(63)$ & $173(60.9)$ & $111(39.1)$ & \multirow[t]{2}{*}{0.927} \\
\hline University/TAFE & $167(37)$ & $101(60.5)$ & 66 (39.5) & \\
\hline \multicolumn{5}{|l|}{ Father's age (years) } \\
\hline$>33$ & 232 (53.2) & $151(65.1)$ & $81(34.9)$ & \multirow[t]{2}{*}{0.050} \\
\hline$\leq 33$ & $204(46.8)$ & $114(55.9)$ & $90(44.1)$ & \\
\hline \multicolumn{5}{|l|}{ Father's country of birth } \\
\hline Australia & $198(45.1)$ & $121(61.1)$ & 77 (38.9) & \multirow[t]{2}{*}{0.980} \\
\hline Other & 241 (54.9) & $147(61.0)$ & $94(39.0)$ & \\
\hline \multicolumn{5}{|l|}{ Father's highest education level } \\
\hline High school & $281(64.3)$ & $176(62.6)$ & $105(37.4)$ & \multirow[t]{2}{*}{0.377} \\
\hline TAFE/tertiary & $156(35.7)$ & 91 (58.3) & $65(41.7)$ & \\
\hline Father's employment status & & & & \\
\hline Full/part time & $366(83.8)$ & $218(59.6)$ & $148(40.4)$ & 0.135 \\
\hline Other (at home/student/unemployed) & 71 (16.3) & 49 (69.0) & $22(31.0)$ & \\
\hline Siblings & & & & \\
\hline No siblings & $152(33.7)$ & $84(53.3)$ & $68(46.7)$ & 0.019 \\
\hline 1-2 sibling & $240(53.2)$ & $145(60.4)$ & $95(39.6)$ & \\
\hline $3+$ siblings & $59(13.1)$ & 45 (76.3) & $14(23.7)$ & \\
\hline Household income after tax $(\$ A)$ & & & & \\
\hline$<25000$ & $51(12.9)$ & $31(60.8)$ & $20(39.2)$ & 0.945 \\
\hline $25000-75000$ & $217(54.8)$ & $127(58.5)$ & 90 (41.5) & \\
\hline $75001-105000$ & $87(22)$ & $54(62.1)$ & 33 (37.9) & \\
\hline$>105000$ & $41(10.4)$ & $25(61.0)$ & $16(39.0)$ & \\
\hline Primary language at home & & & & \\
\hline English & $317(70.3)$ & $82(60.6)$ & $52(39.4)$ & 0.901 \\
\hline Other language & $134(29.7)$ & $192(61.2)$ & $125(38.8)$ & \\
\hline Outdoor activity equipment at home & & & & \\
\hline Yes & $382(84.7)$ & $242(46.4)$ & $140(53.6)$ & 0.008 \\
\hline No & 69 (15.3) & $32(63.4)$ & 37 (36.6) & \\
\hline Stories read per week & & & & \\
\hline$\leq 3$ & $167(37.4)$ & $91(54.5)$ & $76(45.5)$ & 0.024 \\
\hline$>3$ & 279 (62.6) & $182(65.2)$ & $97(34.8)$ & \\
\hline Number of outings per week & & & & \\
\hline $5+$ & $286(63.6)$ & $191(66.8)$ & 95 (33.2) & 0.001 \\
\hline $0-4$ & $164(36.4)$ & $83(50.6)$ & $81(49.4)$ & \\
\hline Childcare & & & & \\
\hline Centre-based care & $75(16.8)$ & $50(66.7)$ & $25(33.3)$ & 0.093 \\
\hline Non-centre-based care & $121(27.1)$ & $62(51.2)$ & $59(48.8)$ & \\
\hline Mixed care (both centre and non-centre based) & $299(6.5)$ & $18(62.1)$ & $11(37.9)$ & \\
\hline No care & $222(49.7)$ & $141(63.5)$ & $81(36.5)$ & \\
\hline
\end{tabular}


Table 2 Associations between sociodemographic characteristics, the home environment and more than 2 hours of screen use daily

\begin{tabular}{|c|c|c|}
\hline Variable & OR $(95 \% \mathrm{Cl})$ & p Value \\
\hline \multicolumn{3}{|c|}{$\begin{array}{l}\text { Whether mother has a } \\
\text { partner }\end{array}$} \\
\hline No partner & $4.32(1.67$ to 11.15$)$ & 0.003 \\
\hline Has a partner & 1 & \\
\hline \multicolumn{3}{|l|}{ Father's employment } \\
\hline Full/part time & 1.96 (1.09 to 3.52$)$ & 0.025 \\
\hline $\begin{array}{l}\text { At home/student/ } \\
\text { unemployed }\end{array}$ & 1 & \\
\hline \multicolumn{3}{|l|}{ Number of siblings } \\
\hline No siblings & 2.44 (1.20 to 4.94$)$ & 0.014 \\
\hline 1-2 siblings & 2.08 (1.06 to 4.08$)$ & 0.034 \\
\hline 3+ siblings & 1 & \\
\hline \multicolumn{3}{|c|}{ Outdoor equipment present } \\
\hline No & 1.89 (1.08 to 3.34$)$ & 0.027 \\
\hline Yes & 1 & \\
\hline \multicolumn{3}{|c|}{ Number of weekly outings } \\
\hline $0-4$ & 2.08 (1.37 to 3.17$)$ & 0.000 \\
\hline$>4$ & 1 & \\
\hline
\end{tabular}

Television can be used by parents as entertainment and a babysitter/distraction for children while they are completing other tasks. Mothers without a partner may have less support in the home and therefore may rely more on television while they are busy. Similarly fathers who are employed may have less time available to spend with the child and to support the mother. Having a reduced number of outings was associated with more screen time, perhaps as more time spent in the home increases the opportunities of being exposed to television. More siblings in the home may encourage other forms of activity displacing screen time. Alternatively more siblings may decrease the availability or access of the screen to infants thereby reducing exposure. Studies on siblings have been equivocal with one systematic review finding no association (in infants aged 0-36 months), and another study finding $>2$ hours of television use in adolescents with siblings. ${ }^{12-14}$ These studies have also shown no association between children living in one or two parent households. ${ }^{12}$ Different comparison groups (especially age groups), differences in the categorisation or coding of variables, and recall errors may account for the lack of consistency between our study results with findings from other studies. ${ }^{12-14}$

We found associations between the presence of activity equipment in the house and reduced screen time. Activity equipment in the home may encourage children to engage in more activity (as opposed to sitting in front of a screen), displacing sedentary time spent on screens. Results of studies investigating physical activity and screen time have been equivocal. Some have shown that in older children, increased physical activity reduced daily screen time. ${ }^{58}$ However, a systematic review in children aged 3-5 years found no associations between outdoor playtime and screen time. ${ }^{20}$ Differences in findings may be from how outdoor activities were measured or for reasons already cited.

Contrary to other studies, parental reports of reading fewer than three stories weekly to children were found to be (marginally) non-significant in our regression model ( $p=0.06$, data not shown). Cognitive stimulation activities (eg, time parents spent reading to children) that require parental engagement have previously been found to be associated with reduced screen time exposure in children <3 years of age. ${ }^{12}$ Increased parental involvement in their child's activities may result in less screen time exposure due to parental views on screen media exposure and also less free time that would have otherwise been taken up by screen use.

Associations between infant gender; maternal country of birth, age, education and employment status; paternal education and age; primary language spoken at home; and household income, and screen time were not significant. This is consistent with other published studies and systematic reviews. ${ }^{12-14}$ A systematic review on nonparental childcare found no association with screen time in children 0-36 months of age. ${ }^{12}$ Our study also found no association between whether a child has full-time centre-based care, full-time non-centre-based care, mixed care or no care.

Excess screen time in children is concerning given the increasing rates of health concerns as a consequence, particularly in developed countries with rising obesity rates. Watching television for more than 2 hours daily has been associated with a poor diet; low physical activity levels and reduced cognitive development in chil-

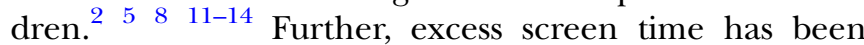
found to be associated with higher rates of behavioural problems. $^{9} 10$ In 2014, the NSW Ministry of Health initiated a Strategic Health Policy which included guidelines for screen viewing in infants, children and young people so as to counter any negative impact on the health and well-being in these groups. ${ }^{21}$

Screen media use has changed markedly in the past 5 years with the introduction of the internet as well as smart phone technology and this challenges parents trying to regulate screen exposure in their children. The impact of these new devices is unknown in younger children, but based on existing evidence, public health interventions to target this ever-growing problem is needed. ${ }^{4}$

\section{Strengths and limitations}

The major strength of this study is that it uses a prospective sample, where we were able to link participant EMR data with the study data thereby collecting individual-level data on a large birth cohort with follow-up at 18 months of age. Further, this allowed for a comprehensive analysis of representativeness of the cohort highlighting any potential biases. As our birth cohort was broadly representative of mothers and infants attending the postnatal wards from which they were recruited, it would be reasonable to postulate that 
the household income, employment and educational levels would be similar for eligible participating and non-participating families. ${ }^{19}$

This study is one of very few studies to investigate screen time in children $<2$ years of age, a critical time in cognitive development. There are significant developmental differences between infants and older children which is why national guidelines for daily screen viewing differ for different age groups. Furthermore, risk factors may be more relevant in certain age groups and not others, an important reason for studies to conduct analyses stratifying by children's age. ${ }^{12} 20$

Our study relied on self-reporting by parents, similar to most other such studies, and therefore recall bias is a possibility. A further potential measurement error from our study arose with the categorisation of screen time where the first two options for reporting screen time were listed as ' $0-2$ ' and ' $2-4$ hours' daily. Parents completing this question could have selected either of the two options if their child's screen time was exactly 2 hours. This could result in either a differential measurement error (parents would be more likely to select the ' $0-2$ hours' option) or a non-differential measurement error. Either way the bias would be towards the null.

A significant limitation of the WMG study was the differential participation at follow-up with challenges in contacting participants for the 18-month follow-up. These included frequent changes in phone numbers and having to make numerous attempts for successful phone contact necessitating significant resources. Although our baseline cohort was representative of the population it sampled at each of the follow-up periods, we were less likely to collect data from those mothers and infants at greater psychosocial risk, thereby introducing differential participation in the follow-up component of our study impacting the studies ability to generalise it's findings. There was no differential participation found for those mothers from diverse cultural backgrounds and non-English-speaking households at the 18-month follow-up. ${ }^{19}$

\section{CONCLUSION}

We have shown that a high proportion of very young children in SWS are being exposed to excessive amounts of screen time. Correlations with excess screen time have also been identified. As few studies have been conducted on screen time in children under the age of 2 years, this study contributes to the limited body of evidence in this area of growing concern. The amount of screen time in children is concerning given the evidence demonstrating adverse cognitive, developmental and health outcomes when the guidelines are exceeded.

Given that children who are high television viewers tend to remain so later in life and that childhood television viewing is associated with overweight and poor cardiorespiratory fitness independent of their adult television viewing levels, it is critical to promote public health awareness and education among parents about the adverse consequences of excessive screen time on longer term health, cognition and behavioural outcomes. $^{2} \quad 8 \quad 9$ Further, population-based, prospective studies on viewing times, content, risk factors, and its short-term and long-term effects would contribute significantly to the evidence base already available, so that public health efforts can be targeted to improving the health and well-being of children.

Author affiliations

${ }^{1}$ Department of Community Paediatrics, South Western Sydney Local Health District, Liverpool, New South Wales, Australia

${ }^{2}$ Epidemiology Group, Healthy People and Places Unit, South Western Sydney Local Health District, Liverpool, New South Wales, Australia

${ }^{3}$ Ingham Institute for Applied Medical Research, Liverpool, New South Wales, Australia

${ }^{4}$ School of Public Health and Community Medicine, University of New South Wales, Sydney, New South Wales, Australia

${ }^{5}$ Sydney Children's Hospitals Network, Westmead, New South Wales, Australia

${ }^{6}$ University of New South Wales, Sydney, New South Wales, Australia

${ }^{7}$ South Western Sydney Clinical School, University of New South Wales,

Sydney, New South Wales, Australia

${ }^{8}$ Academic Unit of Child Psychiatry South Western Sydney Local Health

District (AUCS), Liverpool, New South Wales, Australia

${ }^{9}$ School of Psychiatry \& Ingham Institute, University of New South Wales, Sydney, New South Wales, Australia

${ }^{10}$ Olga Tennison Autism Research Centre, La Trobe University, Melbourne,

Victoria, Australia

${ }^{11}$ Department of Paediatrics, University of Melbourne, Melbourne, Victoria,

Australia

${ }^{12}$ Developmental Medicine, Royal Children's Hospital, Australia

${ }^{13}$ Murdoch Children's Research Institute, Australia

${ }^{14}$ NSW Kids and Families, NSW Ministry of Health, North Sydney, New South Wales, Australia

Acknowledgements The authors thank Professor Margot Prior for her contribution to the development of the research proposal, colleagues from the child and family health nurses in the Liverpool/Fairfield/Bankstown areas and their managers Trish Clarke, Victoria Blight and Wendy Geddes, the staff of the postnatal wards at Liverpool and Bankstown hospitals, andt he staff at the Clinical Information Department at Liverpool hospital. The authors also acknowledge the support of Deborah Beasley and April Darling for liaison with NSW Ministry of Health Department of Kids and families, Alexandra Hendry (Research officer, Early Years Research Group) for her help in ethics submission, as well as Pankaj Garg, Wendy Callins and Lynne Ireland for their contribution to the qualitative component of the study. The authors are grateful to all the participants for their time and assistance in this research.

The 'Watch Me Grow' study group comprises of investigators Valsamma Eapen, Katrina Williams, Cheryl Dissanayake, Bin Jalaludin, Sue Woolfenden, John Eastwood, Stewart Einfeld, Elizabeth Murphy, Kate Short and Natalie Silove, as well as research associates Joseph Descallar, Stephen Matthey, Rudi Črnčec, Amelia Walter, My Trinh Ha, Anne McKenzie and research staff Annabel Marsh, Annette Barone, Ayesha Sadozai, Banosha Yakob, Bronwyn Overs, Cherie Butler, Emma Axelsson, Feroza Khan, Janelle Cleary, Laura Nichols, Mary Ha, Nicole Lees, Snehal Akre, Susan Harvey, Olivia Wong, Tara Shine, and Van Nguyen.

Contributors VE, SW, KW, BJ, CD, EM, JE, DB, RC, KS, NS, SE developed the study design and participated in the preparation of the manuscript. EA, BO, $\mathrm{AH}, \mathrm{AW}$ and JD provided assistance in developing the study protocols and databases, and participated in manuscript preparation. MC, BJ, JD analysed the data. MC, BJ, JD, VE, SW, KW, BJ, CD, EM and JE participated in the preparation of the manuscript. All authors have read and approved the content of the manuscript. The 'Watch Me Grow' study group provided assistance in developing the study protocols and data collection. 
Funding This study (APP 1013690) was funded by the NH\&MRC in Australia, through a partnership grant with the New South Wales Department of Health, Kids and Families and in-kind support from University of New South Wales, La Trobe University, South Western Sydney Local Health District and Sydney Children's Hospital Network.

Competing interests None declared.

Ethics approval The University of New South Wales Human Research Ethics Committee.

Provenance and peer review Not commissioned; externally peer reviewed.

Data sharing statement No additional data are available.

Open Access This is an Open Access article distributed in accordance with the Creative Commons Attribution Non Commercial (CC BY-NC 4.0) license, which permits others to distribute, remix, adapt, build upon this work noncommercially, and license their derivative works on different terms, provided the original work is properly cited and the use is non-commercial. See: http:// creativecommons.org/licenses/by-nc/4.0/

\section{REFERENCES}

1. Department of Health. National Physical Activity Recommendations for Children 0-5 years. 2013. http://www.health.gov.au/internet/main/ publishing.nsf/content/health-pubhlth-strateg-phys-act-guidelines (accessed Sep 2015).

2. Zimmerman FJ, Christakis DA. Children's television viewing and cognitive outcomes: a longitudinal analysis of national data. Arch Pediatr Adolesc Med 2005;159:619-25.

3. Certain LK, Kahn RS. Prevalence, correlates, and trajectory of television viewing among infants and toddlers. Pediatrics 2002;109:634-42.

4. The Royal Australian College of Physicians: Paediatrics and Child Health Division. Children and the media: advocating for the future. Paediatric Policy, 2004

5. Salmon J, Campbell KJ, Crawford DA. Television viewing habits associated with obesity risk factors: a survey of Melbourne schoolchildren. Med J Aust 2006;184:64-7.

6. NSW Health. New South Wales Population Health Survey 2011-12. Centre for Epidemiology and Research. Sydney: NSW Department of Health, 2009.

7. Tremblay MS, LeBlanc AG, Kho ME, et al. Systematic review of sedentary behaviour and health indicators in school-aged children and youth. Int J Behav Nutr Phys Act 2011;8:98.
8. Hancox RJ, Milne BJ, Poulton R. Association between child and adolescent television viewing and adult health: a longitudinal birth cohort study. Lancet 2004;364:257-62.

9. Ozmert E, Toyran M, Yurdakök K. Behavioral correlates of television viewing in primary school children evaluated by the child behavior checklist. Arch Pediatr Adolesc Med 2002;156:910-14.

10. Yousef S, Eapen V, Zoubeidi T, et al. Behavioral correlation with television watching and videogame playing among children in the United Arab Emirates. Int J Psychiatry Clin Pract 2014;18:203-7.

11. Thakkar RR, Garrison MM, Christakis DA. A systematic review for the effects of television viewing by infants and preschoolers. Pediatrics 2006;118:2025-31.

12. Duch H, Fisher EM, Ensari I, et al. Screen time use in children under 3 years old: a systematic review of correlates. Int $J$ Behav Nutr Phys Act 2013;10:102.

13. Hardy LL, Baur LA, Sarah PG, et al. Family and home correlates of television viewing in 12-13-year-old adolescents: the Nepean Study. Int J Behav Nutr Phys Act 2006;3:24.

14. Hoyos Cillero I, Jago R. Systematic review of correlates of screen-viewing among young children. Prev Med 2010 $51: 3-10$

15. Glascoe F. Collaborating with parents: using Parents' Evaluation of Developmental Status (PEDS) to detect and address developmental and behavioural problems. 2nd edn. Nolensville, TN: PEDSTest. com, LLC, 1998. http://www.pedstest.com (accessed Sep 2013).

16. Schmidt ME, Pempek TA, Kirkorian HL, et al. The effects of background television on the toy play behavior of very young children. Child Dev 2008;79:1137-51.

17. Eapen V, Woolfenden S, Williams K, et al. Are you available for the next 18 months?"-methods and aims of a longitudinal birth cohort study investigating a universal developmental surveillance program: the 'Watch Me Grow' study. BMC Pediatr 2014;14:234.

18. NSW Health. South Western Sydney Local Health District. Health Profile of Local Communities. NSW Government, 2014. (accessed Jun 2015).

19. Woolfenden S, Eapen V, Axelsson E, et al. the 'Watch Me Grow' Study Group. Who is our cohort: recruitment, representativeness, baseline risk and retention in the "Watch Me Grow" study? BMC Pediatr 2016;16:46.

20. Hinkley T, Salmon J, Okely AD, et al. Correlates of sedentary behaviours in preschool children: a review. Int J Behav Nutr Phys Act 2010;7:66

21. NSW Kids and Families. Healthy safe well: a strategic health plan for children, young people, and families 2014-24. NSW Health, 2014. (accessed Apr 2016). 